\title{
O século de Taylor, Lênin e Freud*
}

Yves Cohen

Tradução de Dorothée de Bruchard

* Texto originalmente publicado em Alliage, n. 20-21, outono-inverno de 1994, pp. 88-104, sob o título "O século Xx começa em 1900: ciências, técnicas, ação". Esta versão suprime o primeiro parágrafo e acrescenta a nota $3 \mathrm{e}$ algumas referências bibliográficas.
O início do século XX assiste a uma série de grandes inovaçōes, deslocamentos e remanejamentos em inúmeros campos. Em 1903, a publicação de Shop management [Administração de oficinas] pelo norte-americano F. W. Taylor (1856-1915) assinala a fundação do taylorismo. A fundação do leninismo é assinalada em 1902 pela publicação de Que fazer?, do russo V. I. Lênin (1870-1924). Nessas datas e com essas obras, pode-se dizer que cada um deles aperfeiçoou um corpo de conhecimentos e preceitos, métodos de intervenção e técnicas, uma ciência de ação que os distingue radicalmente de seus predecessores em suas áreas. Nessa mesma época, a psicanálise apresentava igualmente sua técnica e suas regras fundamentais, estabelecendo as bases de mais uma ciência prática: em 1900, Freud (1856-1944) publica em Viena $A$ interpretação dos sonhos, livro fundador da nova disciplina.

A partir de então, determinada prática de organização da produção de objetos comercializáveis será taylorista se formalizar, num escritório de organização e métodos, o pensamento sobre o trabalho, sua preparação, a elaboração das normas que irão contê-lo. Da mesma forma, certa prática de organização 
1. É o que o psicólogo Henri Wallon formulou de maneira interessante, embora datada, num texto redigido em 1934: o desenvolvimento técnico "pressupōe um esforço especulativo voltado para o conhecimento das regras de conduta que permitem alcançar o resultado almejado, isto é, em última instância, para o conhecimento das leis que regem o curso das coisas" (Wallon, 1936, p. 136).

2. Sobre Viena em torno de 1900 , ver Schorske (1988). do governo e da luta pelo poder será leninista se um partido comunista exercer o papel de dirigente do povo - a começar da classe operária -, e uma prática de organização do equilíbrio psicoafetivo será freudiana se estiver pautada pela relação entre psicanalista e paciente, estando o primeiro sentado numa poltrona à cabeceira do divã em que o segundo estará deitado.

Toda técnica elabora regras que assegurem sua eficácia ${ }^{1}$ e que são enunciadas pelos próprios técnicos em torno de uma regra central de efetividade. Tal como as técnicas, essas três ciências da ação aperfeiçoaram suas normas e formularam sua regra central de efetividade. A regra da prática de organização taylorista é a do respeito pelo tempo prescrito, a do leninismo é a da adesão e a do freudismo, a da livre associação (tornarei a evocar as regras do dispêndio mínimo de energia humana, da contemplação e, também, as regras da existência, da nomeação, do cálculo).

Será que esse século começa, de fato, em torno de 1900, ano da morte de Nietzsche?

Os anos em torno de 1900 assistem a outros importantes abalos que irei mencionar aqui como quem esboça um cenário, ainda que devessem na verdade ser tratados em termos de ressonâncias e correspondências, tal como Henri Wallon procura brilhantemente fazer num texto de 1934, que ainda conserva grande pertinência (cf. Wallon, 1936) ${ }^{2}$. Pierre e Marie Curie descobrem o rádio em 1898. Max Planck estabelece a teoria dos quanta em 1900. Em 1905, Einstein formula a teoria da relatividade restrita e Niels Bohr, em 1911, a da estrutura atômica. Revolução na física. Por volta de 1900, estatísticos ingleses, formalizada a teoria da inferência, tornam possível a estatística matemática. Ainda por volta de 1900, William James difunde o pragmatismo que subordina o juízo de verdade à apreciação da eficácia. Em 1906, em Genebra, Ferdinand de Saussure dá início aos cursos sobre a linguagem, a língua e o signo que constituirão a matéria do Curso de linguística geral e inauguram a linguística estrutural.

Numa outra ordem, o olho humano precisa habituar-se à imposição do tempo, que lhe faz assumir o risco da mentira. Para estudar os movimentos da vida, incluindo o voo dos pássaros e, desde já, os movimentos do trabalho, Jules Marey inventa, em 1883, a cronofotografia. Segue-se a invenção dos Lumière, em 1895. No mesmo momento, no que tange à produção, o olhar de Taylor decompõe, na linha do tempo, os movimentos de longa experiência dos operários mestres do método a fim de recompô-los, mais eficientes, mais rápidos, mais econômicos, mais próximos de um tempo de produção verdadeiro. Quanto à arte, com Les demoiselles d'Avignon, em 
1907, Picasso começa a decompor seu olhar no espaço, rompendo as imagens perfeitas para recompô-las ainda mais verdadeiras, cubistas, quando em 1909 se dá o acontecimento Kandinski em Murnau, o abstrato. Cada um deles, de seu ponto de vista, está em vias de criar o belo.

Já para o ouvido humano, a imposição do tempo, tal como a mentira, é mais familiar. Fonógrafo e telefone ainda são invençōes recentes no início do século. Transmitem o som verdadeiro. Mais recente ainda é o telégrafo de Marconi. No momento em que, para fazer a revolução, Lênin ouve a palavra espontânea, voluntária, de modo a devolvê-la com algo mais de verdade, mais próxima de um significado verdadeiro, Schönberg, para ouvir sua música, quebra e decompõe a antiga tonalidade. Isso ocorre em 1908, com o último movimento do Segundo Quarteto de Cordas. Ele funda, assim, a possibilidade de toda música serial e da música contemporânea. Cada um deles, de seu ponto de vista, está em vias de criar o belo.

Que cenário se define em meio às agitações aparentemente fortuitas daqueles $\operatorname{anos}^{3}$ ?

Voltando ao trio inicial, aquele formado por Taylor, Lênin e Freud, assistimos de fato à criação de um dispositivo comum: uma singular disposição que permite a ação, que permite que se constitua um saber oriundo da prática e para ela orientado e que permite que seja colocado em atos. Esse dispositivo técnico, como todo dispositivo aliás, possui forte dimensão espacial. O escritório de organização e métodos, o partido de vanguarda e a poltrona constituem locais isolados em que se opera um trabalho de pensamento, em que se elaboram verdades, interpretações e normas. Estas serão aplicadas na fábrica, entre as massas revolucionárias, no divã: aí se fará o trabalho. A criação não pertence à ordem do organograma, nem à da cognição apenas, mas à de uma racionalidade inseparável de uma ação distribuída ${ }^{4}$. Afora isso, que ainda deverá ser aperfeiçoado, tudo é diferente, mas o desafio está em compreender de que forma tais questôes se articulam historicamente.

Partindo da prática da organização taylorizada, vou agora proceder ao isolamento dos princípios de análise passíveis de serem aplicados a outros grandes modos de ação, desde que com um considerável esforço de especificação dos próprios princípios de análise.

É a instituição formal de um escritório de organização e métodos o que opera a transição das empresas para a era taylorista, entre os principais fabricantes automobilísticos no final da Primeira Guerra Mundial e no início do pós-guerra. A difusão da influência desse escritório nas oficinas e seu crescimento por setor ocorrem lentamente. O importante é ele agora
3. O século aqui considerado começa, portanto, em 1900, mais cedo do que "o curto século Xx" de Eric Hobsbawm (2009) [nota acrescentada em 2012].

4. Tais dispositivos são evidentemente datados. São, hoje, fortemente contestados ou estão desaparecendo, mas assumem a figura do Centauro, imagem cristalizada da primeira aparição, numa guerra, de um cavalo montado, outro dispositivo técnico. Apesar de o ato de comandar cavalos ter se tornado ordinário, o choque persiste como mito: está sempre presente. 
existir formalmente e ser incluído de modo refletido num conjunto de outras instituiçōes.

Afirmar, então, que está em funcionamento um sistema de organização taylorista equivale simplesmente a dizer que nele opera "a peça mestra" do aporte de Taylor às práticas de organização da produção: o escritório de organização e métodos (cf. Mottez, 1966, p. 136). Isso não significa que se trata do "sistema Taylor" em si e em pessoa: a própria maneira de apreender o taylorismo é uma variável da ação organizacional, de sua relação com a teoria. A designação "taylorista" não permite dispensar a análise do regime organizacional em todas as suas componentes, nem estudá-lo tão somente pela abordagem da "introdução ao taylorismo". Não existe, com efeito, um modo de organização puro, genérico, abstrato, que se possa aplicar mais ou menos bem, com mais ou menos perfeição ou de antemão. O que existem são sistemas efetivos, em carne e osso, em ato, nas unidades específicas de produção, uma unidade de produção definida pelo campo em que se desdobra um sistema organizacional e pelo âmbito em que tal sistema pode ser analisado. Assim, por exemplo, o grupo das fábricas da Sociedade Anônima dos Automóveis e Bicicletas Peugeot (prédios, instalações, incluindo todos os materiais e todos os funcionários) na regiáo de Doubs: opera-se aí uma vontade organizadora e unificadora (cf. Cohen, 1986, 2001).

É possível especificar a relação estabelecida entre esses sistemas e as teorias gerais. Atente-se, no entanto, para não cair na mesma armadilha que "os teóricos clássicos [que] fundamentavam seu projeto na ideia de que existiam leis organizacionais independentes dos sistemas de produção e dos objetivos da empresa" (Mottez, 1975, p. 95). Dogmas ou guias de ação: assim como no marxismo, a questão se colocava aos técnicos qualquer que fosse o nível em que se encontrassem.

\section{Dimensões}

\section{A unidade $e$ a identidade}

A natureza do complexo organizacional depende, em primeiro lugar, da natureza do produto. Assim, não será mero acaso a indústria automobilística ter se transformado em "caso simbólico" quando se trata de estudar a produção em larga escala e a organização taylorista do trabalho.

O automóvel é o objeto-modelo, e a indústria automobilística, o ramo industrial modelo, o pattern dos sistemas organizacionais da era taylorista. 
A fabricação de automóveis é aquela em que as variáveis organizacionais são aplicadas de forma mais harmoniosa, típica e equilibrada.

O automóvel, como todo campo de exercício de uma técnica, não possui uma variável específica. Ele simplesmente confere a cada variável um valor particular e as hierarquiza a seu modo, em se tratando de hierarquia. Cada fabricante possui seu próprio projeto, esquema, modo de exercício das variáveis. Cada um deles compõe seu próprio regime segundo uma espécie de one best way específico do automóvel ${ }^{5}$, mas da perspectiva organizacional bastante amplo, evolutivo, não normativo, em que as variáveis dispõem de uma margem de manobra definida, obviamente ladeada por valas nas quais não cair.

\section{A unidade e a primazia técnica: a especificação}

A primazia técnica de um ramo industrial regulamenta as similitudes entre os sistemas organizacionais das empresas que o compõem. Ela dá à indústria sua unidade técnica.

Inicialmente, o que constitui a especificidade do automóvel em meio a todos os objetos materiais de consumo é o motor a explosão adaptado sobre um chassi dotado de rodas. Isso representa a faceta material da primazia técnica. Esta é dotada, porém, de outra faceta que nada tem de material: o modo de valorização do objeto. O automóvel é, antes de tudo, um veículo individual - e familiar -, um meio extremamente eficiente - ele anda depressa. Esse produto/objeto participa da prática organizadora sob as duas facetas de sua primazia: como unidade material e como suporte de valorização.

O motor é o núcleo material - mecânico - do automóvel. Melhor dizendo, é o seu cerne: o legítimo núcleo mecânico é o chassi, com o motor montado.

Se, por este prisma, considerarmos o obus - que constituiu a maior parte da produção dos fabricantes de automóveis durante a guerra e levou à invenção de um modo organizacional totalmente novo-, obtemos um objeto técnico de um gênero distinto e, ao mesmo tempo, similar. Daquilo que é similar, poderia proceder uma sintaxe do objeto técnico: com efeito, o obus, peça metálica sobre a qual se ajusta o mecanismo de detonação, não pode, sem sua carga (capacidade de destruição) e sem o canhão (dispositivo de projeção), ser considerado um objeto completo destinado a causar a morte com a maior eficácia possível. O objeto fabricado pela Peugeot ou pela Citroën não passa, portanto, em relação a esse objeto técnico completo, do
5. Sobre o destino sociológico do conceito tayloriano do one best way, ver Mottez (1975, pp. 95-96). 
6. Observe-se que, de um ponto de vista tecnológico (semântico, de certa forma), a filiação do pistão que anima o motor a combustão interna não é alheia ao canhão. equivalente ao quadro do chassi em relação ao automóvel, sendo a carga o equivalente das rodas, e o canhão, do motor ${ }^{6}$.

Ora, todas as variáveis organizacionais são perpassadas, direta ou indiretamente, pelas determinações materiais da mecânica automobilística (ou do obus): particularidades mecânicas e químicas dos metais, número e dimensão das peças e conjuntos, precisão de suas cotas, complexidade de montagem, emprego de uma aparelhagem eletromecânica etc.

$\mathrm{O}$ aspecto de veículo individual e familiar eficiente, conferido de imediato ao automóvel - mediação maquínica eficaz e facilmente controlável dos deslocamentos -, é o núcleo de sua utilidade social e de seu valor simbólico, ou seja, de suas formas de valorização. Os demais usos e investimentos vêm se enxertar neste núcleo sociossimbólico: do táxi ao caminhão, do ônibus ao carro de corrida e ao tanque de guerra... Isso ocorre da mesma forma como, sobre o núcleo material, vem se ajustar a carroceria, citoplasma (e ectoplasma) em que a estética e o conforto, assim como a suavidade e eficácia da direção, vêm dar sua contribuição para a identidade material e socioafetiva do produto/objeto.

Por volta da Primeira Guerra Mundial, estava concluída a instauração do automóvel como objeto técnico em seu duplo aspecto. No que tange à técnica material, encerrava-se o período das grandes inovações constitutivas do objeto (o dos primeiros inventores). No que se refere à utilidade social e ao valor simbólico, o automóvel continuava sendo um produto conquistador. Ele acumulava valorizações e, também nesse sentido, a guerra assinalava uma virada. O automóvel passou por grandes valorizações: como objeto de lucro e promoção, com a criação de algumas grandes empresas e muitas outras pequenas e médias; como objeto de luxo e de moda, com o dispêndio de certa clientela; como meio de performance e proeza técnica (em seus dois aspectos, humano e material), com a competição esportiva; como poder de transformação econômica, social e militar mediante cerca de vinte anos de propagação, cuja apoteose estava em sua vitoriosa participação na Grande Guerra: os táxis da Marne (Renault), os caminhões (Berliet) abastecendo Verdun, os tanques de guerra (Renault novamente).

Temos aí, portanto, uma variável da prática organizacional constituída por uma dupla relação: com uma entidade material e com uma entidade sociossimbólica. Mas eis que surge uma dúvida quanto à insistência no "duplo", pois esse objeto a ser produzido talvez possua três facetas se, para fins de reflexão, isolarmos duas facetas de sua dimensão sociossimbólica - a utilidade social e o valor afetivo - que, na realidade (a prática do objeto), 
nunca são separadas. Então poderíamos ter como núcleo da utilidade social do automóvel o estreitamento do espaço e do tempo, ou seja, um ganho de potência, e como núcleo de seu valor afetivo, a dominação total (a direção) de um ser - um ser ainda apenas mecânico. E por que não acrescentar mais duas facetas significativas a esse objeto a ser produzido e utilizado? A primeira seria moral, se entendermos por moral as regras sobre o gasto de energia: $o$ núcleo moral do automóvel seria as duas primeiras facetas serem executadas com o menor custo energético possível, ao menos para o operador humano. A última faceta seria a estética. Ela traria harmonia às partes e ao conjunto prático como um todo.

Quatro facetas significativas do objeto praticado e da prática do objeto que seriam, então, ligadas, imbricadas e inseparáveis (embora isoláveis na análise) e às quais corresponderiam produções materiais que seriam elas próprias ligadas, imbricadas e inseparáveis (embora igualmente isoláveis) tal como, por exemplo, a palavra e a fala (cf. Jakobson, 1963).

Qualquer que seja o número de facetas do nosso "poliedro de inteligibilidade" (cf. Foucault apud Perrot, 1980), teremos em mente que elas também dizem respeito ao afetivo, ao moral e ao estético.

O fato é que essa variável da relação com o objeto produzido especifica todas as demais variáveis no one best way automóvel. Ela lhes dá o caráter ou modalidade de especificação, se considerarmos que a relação de cada variável com todas as demais consiste em contaminá-las e, portanto, conferir-lhes um caráter (ou modalidade) singular. A circulação dessas modalidades oriundas de cada uma das variáveis determina a compatibilidade entre as variáveis do sistema e lhe dá coerência.

O exercício dessa relação é institucionalizado e regrado. Assim é, naturalmente, na concepção dos modelos que devem identificar a marca, aperfeiçoando e desenvolvendo o produto de modo a atender a essas valorizaçóes, ou mesmo antecipar-se a elas. Da mesma forma, a valorização da qualidade do produto, em suas duas espécies, é a base da comercialização (o nome, ou seja a marca precisa concentrar tudo). A organização taylorizada formaliza o vínculo entre a natureza do produto e a organização da empresa.

\section{A identidade, os Estados Unidos e a Ford: a padronização}

A organização do vínculo com os Estados Unidos, no que tange à produção, constitui como que o contraponto inseparável daquela do vínculo com o produto, como se o automóvel estivesse doravante indefectivelmente 
vinculado a esse país. Cada fabricante estabelece sua relação com os Estados Unidos a fim de se familiarizar com as modernas técnicas de produção e de reforçar o aprendizado organizacional de seus quadros. A passagem por Detroit, onde opera a Ford, tornou-se obrigatória: esta cidade é homóloga a Moscou e Viena.

A relação com o lugar onde nasceu o taylorismo é uma variável cujo domínio é decisivo para o organizador taylorista. Ela é especificada no automóvel. É esse o feito fordista. Ford é o integrador de um sistema taylorista em um produto - este exato produto - e em uma empresa. Ele singularizou o que se apresentava como um sistema geral. Esse vínculo especial data de 1908, da breve crise que se instaura no centro da nova indústria vinda da Europa e que, nesse país ainda espaçoso, pôde queimar etapas. O feito fordista é primeiramente o modelo único, o Ford T, que data daquele ano. $\mathrm{O}$ automóvel padronizado. O ser mecânico clonado. Organização e produção da repetição da identidade no real.

A variável do vínculo com os Estados Unidos e com o fordismo confere a todas as outras variáveis a modalidade de padronização (tanto dos modos de produção como dos produtos). A partir daí, o produto será igualmente concebido, por Ford, em função de sua produção. Deverá ser capaz de ser fabricado em grande escala: uma nova determinação que o constitui. Efeito da organização sobre o produto, da técnica de organização sobre o objeto técnico.

O organizador é dotado, portanto, de duplo conhecimento e de dupla paixão: pelo automóvel em si e por sua produção. Vínculo com o produto no qual se encontra a unidade do sistema prático, vínculo com o local onde a produção foi integrada e especificada, onde se encontra sua identidade. Recordemos as palavras de Marcel Mauss: a "especificidade é o caráter de todas as técnicas" (no sentido de conformação por um local) (Mauss, 1983, p. 367).

\section{0 espaço governado pelo tempo}

Espacialização e localização

O objeto é a base da definição de um one best way organizacional que, em contrapartida, contribui para defini-lo. Da mesma forma, o espaço, campo de aplicação da ação de organizar, impõe-se ao objeto e é transformado por ele.

Antes de Taylor, tanto a concepção do trabalho como a definição do espaço, assim como o vínculo entre elas, eram empíricas e espontâneas, ficando ao sabor da relação de forças entre os operários, com suas práticas coletivas de 
trabalho e com sua hierarquia tradicional. Ambas se tornam um campo de ação único, mas articulado pelos escritórios de organização e métodos. Estes redefinem o campo e lhe conferem uma coesão lógica. Uma vez formalizado o imperativo organizacional - a otimização da produção -, ele passa a operar.

O campo organizacional é espaço. Um espaço cheio, composto por matérias e homens, suas posições, seu número, suas dimensões, seu volume, que se manifestam em movimentos. É constituído por relações materiais, relações humanas e relações entre homens e matérias. O sistema operacional nunca considera cada polo separadamente: nem a disposição das matérias, a forma dos prédios, os circuitos, sem nele inscrever os homens e suas relações; nem as relaçôes entre os homens, entre seus cargos e os cargos ou setores que os cercam, sem inscrevê-los numa repartição espacial bem material. Os pares homens/matérias constituem as unidades de produção de que a organização do espaço trata de determinar a natureza, as dimensões e as conexões otimais: um ambiente para os movimentos e fluxos. Movimentos e fluxos das matérias em transformação, movimentos e fluxos mais complexos dos homens e de suas práticas e comunicações (quando não de seus olhares e sentimentos...).

Todas as determinações são convertidas em distâncias a percorrer. Tais distâncias são organizadas em função da produção: o espaço é medido, espacializado. Existem duas funçôes primeiras: determinar a escala e a concentração da produção, por exemplo, organizar as relações entre as dimensōes dos prédios, das oficinas, as distâncias externas e internas, a interpenetração dessas distâncias, o volume de produção (previsto e efetivo), os recursos exigidos e o número de homens. Esta é uma tarefa para setores especializados e especialistas, engenheiros, arquitetos e demais técnicos que institucionalizam a variável espaço.

Além da espacialização há, porém, a localização.

Tomemos o exemplo da Peugeot, na qual o engenheiro Mattern criou uma organização formalizada em 1917. O campo que lhe ofereceram era composto por quatro fábricas na região de Doubs.

No que diz respeito à matéria, têm-se os prédios das oficinas e escritórios e demais locais; os equipamentos e máquinas; as ferramentas e todos os materiais de despesas gerais; as matérias-primas e, em transformação, a energia e os meios de se produzir esta energia; a ponta de torno e o armário do vestiário se houver; os impressos e outros escritos ligados à produção; os telefones; sem esquecer o charco lamacento atrás da fábrica de Sochaux; a distância de nove quilômetros entre esta fábrica e a outra em Beaulieu, 
7. O jornal pacifista La Vagueque esse trabalhador leva no bolso está incluído na matéria, até mesmo o bolso está incluído.

8. Por exemplo, "Maison Peugeot", "Maison Renault" etc.

9. Referência ao Cais do Sena, em Paris, onde ficava a fábrica $\mathrm{da}$ Citroën, hoje rebatizado quai André-Citröen [N.T.].

10. Ao fornecer meios de intervenção sobre ele antes inexistentes, Taylor de certa forma inventa esse tempo, tal como Lênin inventa esse proletariado...: é legítimo que ele seja, ao menos provisoriamente, o seu epônimo. $\mathrm{O}$ que não significa que não existiam antes o tempo contado, o proletariado, o inconsciente. e todos os demais fatores materiais de localização (força motriz, entrega das matérias-primas e evacuação dos produtos, proximidade dos locais de residência da mão de obra etc.).

No que tange aos homens, há desde o simples operário marroquino até o diretor, passando pelo zelador, a "operária especializada” em perfuração, originária de e residente em Bondeval, habituada às obras sociais da firma e cujo marido se encontra no front, o ajustador de montagem socialista, recruta especialmente alocado nas fábricas e originário de Lille ${ }^{7}$, o testador famoso e o contramestre detestado. A herança recebida por Mattern, em 1917, faz ainda desses homens e mulheres uma massa em processo de sindicalização acelerada, cujo movimento é dirigido pelos socialistas que representam posiçóes políticas minoritárias. Reivindicaçóes salariais, críticas à organização da fábrica, ameaças de greve e greves animam o que não pode ser considerado apenas como efetivos que deveriam ser distribuídos e classificados. Trata-se de interlocutores em todos os setores da ação organizacional.

Com a organização combinando e regulando os fluxos, os pares homens/ matérias são organizados em uma série de unidades integradas: postos de trabalho, concatenação de postos, oficinas e setores, fábricas, grupos de fábricas, até atingir os limites naturais de um campo organizado por um sistema taylorista: a empresa, ou, em outras palavras, a Marca (para a clientela), em outras palavras a "Maison"8 (para os funcionários). O espaço é identificado por nome próprio - Peugeot, Renault ou Berliet... -, e identifica todas as variáveis.

O espaço da organização não é, nesse estágio do sistema, intercambiável. Ele faz o sistema e é feito por ele. Está inscrito, localizado. A variável, então, consiste não apenas na construção do espaço, mas também na decisão e na capacidade de se inscrever, ou não, em um território dado, numa geografia: a região de Montbéliard, Billancourt, Vénissieux, o cais de $\mathrm{Javel}^{9}$...

O campo organizacional taylorista acaso tende, tenta se localizar? Seja como for, ele localiza todas as variáveis.

\section{Temporalização e datação}

A instituição de um sistema taylorista define e estreita o espaço, que é convertido em movimentos e, portanto, em tempo (e, portanto, em custos). Ora, o território do taylorismo é o tempo (assim como o do leninismo, o proletariado e o povo e o do freudismo, o inconsciente).

Trata-se de um tempo inventado. Tal como o espaço, o tempo taylorista é material e humano - inscrito ${ }^{10}$. Tal como o espaço, ele se manifesta em movi- 
mentos (mensurados a partir de um ponto fixo escolhido, a unidade de produção, a oficina, o posto de trabalho, os órgãos de manobra de uma máquina etc.) e também em transformações materiais e práticas humanas. Esse tempo é um tempo-para-a-produção. Por um lado, ele se converte em lucro para o empreendedor através das duas formas de consumo (material e sociossimbólico) do consumidor; por outro, ele é (até certo ponto) convertido em medidas.

\section{(a) Temporalização}

A produção dessas medidas por parte dos especialistas do escritório de organização e métodos é destinada a regrar e regular aquilo de que é composto o tempo: as transformaçóes da matéria e os atos dos homens - tudo aquilo que constitui o trabalho.

A relação do regime organizacional com o tempo é instituída no setor em que é pensado o trabalho: o escritório de organização e métodos. Esta variável temporaliza todas as demais (impregna-as com a medida do tempo e a organização dessas medidas). Ela difunde um tempo taylorista dotado de todas as modalidades que essas próprias variáveis conferem, inclusive a localização ${ }^{11}$ e a espacialização (conversão do espaço em medidas e em organização das distâncias e proximidades).

(b) Matéria transformada e homens livres

Deste modo, a prática organizacional apreende matéria e homens:

- Uma matéria que sofre transformaçôes determinadas a fim de se tornar um objeto comercializável. O espaço de produção existe para produzir, antes de qualquer outro motivo (ele é primeiro, do ponto de vista da ação organizacional, um espaço-para-a-produção).

- Homens que entram em determinadas relações com a matéria e entre si, mas que possuem a liberdade primeira de partir, de deixar o local da dominação (são assalariados). Tal liberdade, por regulamentada que seja, instaura a possibilidade da "ociosidade sistemática", do "refreamento" da produção. Onde não existe a liberdade de partir (como na União Soviética ou em outros países fundados no modelo e regidos pela regra da adesão, por mais maleável que seja essa não liberdade), o refreamento não é um problema pertinente. $\mathrm{O}$ turn-over, ou a rotatividade de pessoal, é fundamental tanto ao capitalismo como ao taylorismo: nos
11. Taylor quer um tempo absoluto, acredita que ele possa existir, mas na verdade sabe que não e que o tempo é localizado. Seus discípulos do pós-guerra não necessariamente saberão que não, ou então não saber não terá tanta importância. Ver a sutil análise de Mottez (1966, pp. 140-42). 
12. Taylor, nas horas vagas, tinha tentado racionalizar o jogo de tênis.
Estados Unidos, segundo o próprio Taylor, a aplicação de seus métodos implica naturalmente que os operários possam partir caso os métodos sejam "injustamente” aplicados (cf. Taylor, 1957, pp. 260-261). É uma resistência elementar, ou melhor, uma protorresistência, uma vez que se trata de evitar o poder. Ter de limitá-lo tem um custo: ele então pode ser também uma prática patronal.

(c) Resistências e datação

A matéria resiste à vontade de produzir. É preciso domar essas resistências. É preciso inventar "técnicas materiais": inscritas, incorporadas à matéria, elas exercerão pressão sobre a matéria... mas também sobre os homens. Pois os homens, assalariados, se não vão embora, resistem em participar da transformação de uma matéria de que não são os donos. Eles serão pressionados pela máquina, que dita a forma como deve ser sua conduta (assim como as bases materiais da direção do automóvel estão inscritas em sua configuração). As técnicas materiais são igualmente sociais.

Mas a pressão da matéria organizada não basta, o homem possui esse triste defeito. Inventam-se então, além disso, "técnicas humanas" que, inscritas nos homens, serão a pressão para os homens e para a matéria. As técnicas humanas também são materiais, de inscrição no espaço material.

A matéria-para-a-produção presta-se à medida dos tempos de transformação, ao cálculo. Com relativa boa vontade, ela é tema das ciências aplicadas e das técnicas elaboradas: a começar, na fábrica, pelo laboratório. Mas o homem se deixa avaliar com mais "má vontade" (expressão que, nos textos, é o sinal universal da resistência). Cerceá-lo com a medida do tempo é mais complexo. Os operários não adotam espontaneamente o tempo taylorista. A própria concepção prática do tempo deles - outra sensibilidade, outra ocupação, outro cálculo, outra palavra, outra moral, outra estética confronta-se rigorosamente com a de Taylor em todas as áreas do jogo na quadra da produção, em todas as variáveis ${ }^{12}$.

O homem, por sua dor, mas também por seu protesto contra a troca desigual, o esgotamento, a repetitividade, a perda do controle..., é, portanto, o limite do cálculo. Ele data esse cálculo, data a medida, data o tempo, o tempo taylorista que é uma tentativa de mensurar, de temporalizar suas práticas. O tempo, como todas as variáveis, possui essa modalidade de ser datado. 
(d) Ciências para a ação

Não vou me estender sobre a função da resistência das classes (pequeno-) burguesas em Lênin e, sobretudo, em Stálin, nem sobre a função das resistências na psicanálise, mas cito, em contrapartida, Andrieux, poeta, respondendo a Bonaparte, primeiro-cônsul, o qual se queixava da independência do tribunato: "Cidadão, você pertence ao instituto, setor de mecânica; sabe perfeitamente que só podemos nos apoiar em algo que resiste"13.

Em oposição ao refreamento industrial, o par homem/máquina se enrijece; as amarras entre um e outro são cientifizadas, quantificadas na verdade; o rendimento do material e do "material humano" ${ }^{14}$ é otimizado: disciplina da matéria aliada a uma disciplina humana.

Em toda a área de contato entre o corpo e o objeto que ele manipula, infiltra-se o poder, amarrando um ao outro. Ele compóe um complexo corpo-alma, corpo-instrumento, corpo-máquina. Estamos bem longe das formas de sujeição que ao corpo só pediam sinais ou produtos, formas de expressão ou resultado de um trabalho. A regulamentação imposta pelo poder é, simultaneamente, construção da operação. E assim se apresenta esse aspecto do poder disciplinar: tem menos uma função de retirada que de síntese, menos de extorsão do produto que de vínculo coercitivo com o aparelho de produção (Foucault, 1975, p. 155).

Aqui, antes de mais nada, trata-se de uma medida de tempo. A mediação suplementar, somando-se à própria máquina, entre o homem e a matéria. A mediação da ciência prática taylorista manifesta-se pela regulagem (a regulação) dos tempos materiais e humanos. É o objeto do trabalho de pensamento do escritório de organização e métodos, a matriz do saber-regulamento taylorista que se comunica com todas as demais variáveis. É, ainda, o pretexto para o nascimento de uma profissão, a dos preparadores, e de uma diferenciação hierárquica em relação aos quadros subalternos funcionais. Formalizados pela existência de um organograma e de setores com relações regulamentadas, esses preparadores e esses quadros subalternos conduzirão como que naturalmente o imperativo organizacional.

As três ciências de ação têm em comum, ainda, o fato de serem ciências de interpretação, o que em si não é original, mas também do retorno da interpretação à fonte (os operários, as massas, o analisante), o que já é mais original. Não uma fonte derivada, diferida, fora de seu espaço natural, na qual transcorre um tempo longo, mas a própria fonte, em seu espaço, e
13. François Andrieux, citado pelo general Louis Maurin num artigo sem título de $X$ Information, n. 10, março de 1930, p. 190.

14. Expressão encontrada nos textos de alguns autores tayloristas. 
15. Na psicanálise, a comunicação da interpretação, que carrega o sentido latente (um significado individual verdadeiro), também é denominada interpretação. Talvez seja aqui o caso de apontar uma diferença essencial entre os dispositivos concebidos, de um lado, por Lênin e Taylor e, de outro, por Freud. Todos rebentam certas práticas ao se inserirem em seu cerne: a relação direta com a produção, a relação direta com a ação política, a relação consigo mesmo. Mas a terceira, que atinge o centro em Viena, só se desdobra na escala individual, remendando, de certa forma, os estragos causados pelas primeiras na escala social, como se, historicamente, um golpe não pudesse ser desfechado sem seu contragolpe.

16. Trata-se de uma lei fundamental do recrutamento dessas ciências de ação: recrutar os técnicos entre aqueles que produzem o tempo verdadeiro, para Taylor (os operários mais qualificados em sua prática), ou a verdade social, para Lênin (os militantes sindicais, quer sejam operários ou não). Da mesma forma, o paciente adquire uma competência na prática da livre associação sob a condução do analista. O produtor dispôe assim de uma linha de promoção definida: o acesso ao controle da produção. Ele tem assim a possibilidade de escolher o contexto de validação ou valorização social de suas práticas nesta ou naquela hierarquia.

17. Recruta alocado por favorecimento num posto não combatente de retaguarda [N. T.]. pela qual só transcorreu o tempo de um ciclo daquilo que os marxistas e, sobretudo, os maoistas denominaram "linha de massa". A fonte se vê destituída dos meios da interpretação. $\mathrm{O}$ operário autônomo e que permanece na fábrica, que domina os métodos e os tempos da produção material e domina os meios da produção comunicacional, entra em outro universo. A interpretação é confiada a especialistas que devolvem, para a fonte, os elementos elaborados em "instrução" (nos diferentes sentidos do termo) e desse retorno decorre outro domínio, o do comando: nesse movimento consiste a ação desses especialistas ${ }^{15}$. Essas ciências de ação são também ciências para a ação da fonte, para o trabalho da fonte e, inseparavelmente, para o poder de seu portador, de seu detentor.

No entanto, cada um a seu modo e na medida em que são fundadores, Taylor e Lênin se colocam a mesma questão formulada por Freud: “Temos o direito e até o dever de prosseguir nossas pesquisas sem nos preocuparmos com sua utilidade imediata. No final, não sabemos onde nem quando o pouco saber que teremos adquirido será transformado em poder terapêutico" (Freud, 1973, p. 237).

Entre os leninistas, a lógica dessa ação científica comporta o ensinamento dispensado: vocês são proletários, o ser mais nobre, o ser fadado ao mais elevado destino. Trair não faz parte de seus interesses fundamentais, mantenham-se proletários e tornem-se, inclusive, um representante profissional, um organizador ${ }^{16}$. Trata-se aí de uma regra anti-turn-over, uma regra para desqualificar o turn-over enquanto problema pertinente. Quando Taylor elabora para todos, enquanto regra de efetividade, uma regra de respeito ao tempo, Lênin formula uma regra de adesão, de fidelidade, à qual é impossível se furtar.

O tempo do mundo (o movimento braudeliano)

\section{A Grande Guerra: a grande datação}

\section{4: o momento de consenso}

A Primeira Guerra Mundial é, em todos os níveis, ritmada, partida ao meio pelo ano de 1917.

Depois de agosto de 1914, sobreveio o momento de consenso. Um momento apenas. Não datado. Quase invisível. Dois, três meses talvez. Bem perto do início da guerra. Antes que apareçam os embusqués ${ }^{17}$ e os 
aproveitadores. Antes da guerra de lama parecer interminável. Durante uma "União Sagrada” ainda virginal. Sem "refreamento" nem "exaustão", nem mesmo, decerto, a rotatividade de pessoal. Da parte de todos, um dispêndio livre e total para a batalha. Sem tempo taylorista com sua contabilidade. Nem proletariado de Marx.

Tudo nasce do que foi esse consenso e do fato dele ter sido quebrado, como não podia deixar de ser. $\mathrm{O}$ investimento estava todo nos poilus ${ }^{18}$, no canhão de 75 mm e na França. A França habitava aqueles soldados e aquele objeto, era levada por eles.

1917: Duas grandes inscrições - Estados Unidos, Rússia

Porém a guerra corre e data o curso das coisas. Por meio dos mortos, centenas de milhares de mortos.

É preciso produzir essa morte de massa. É um caso de indústria: abre-se outra linha de frente, decisiva, a da mobilização industrial, governada pelo socialista Albert Thomas, ministro do Armamento até 1917. É este o homem que, em 1916, declara aos operários da enorme fábrica de armamentos da região de Creusot: "A vitória paira sobre nós, na fumaça que toma conta deste vale. É com vocês, camaradas, que contamos para agarrá-la. A tarefa de vocês é trabalhar até cair, até a morte” (Fine, 1978, p. 309) ${ }^{19}$. Liberdade total de consumir o "material humano", de usar sua força, toda a força, toda a vida. Pressão livremente consentida de se deixar consumir em totalidade pela pátria: durante muito tempo, o refreamento não foi questão pertinente e não houve trabalho para os cronometristas.

Chega-se a 1917, enquanto imperam, na vanguarda e na retaguarda, o grande consumo de homens e, particularmente na retaguarda, nas fábricas, o arbitrário também atestado pelas fontes patronais. $\mathrm{O}$ inverno foi extremamente rigoroso e o aprovisionamento de recursos de aquecimento foi excepcionalmente difícil após três anos de guerra. Assim também o abastecimento, que tende a se desorganizar ainda mais. Tributações e racionamentos ainda estavam engatinhando, já a inflação se acelerava de forma imediatamente perceptível.

O Tsar, quase tão odiado na França quanto o Kaiser, foi derrubado em fevereiro. Iriam os russos manter a jovem Revolução?

A produção de obus não cessou de crescer desde o início da guerra e alcançava, na França, entre março e maio, números extremamente altos: de 6,5 a 7 milhões mensais de obus de $75 \mathrm{~mm}$.
18. Como eram chamados os soldados combatentes da guerra de 1914 [N. T.].

19. Ver também Fridenson (1977). 
Em 16 de abril, ocorre o fracasso total da ofensiva de primavera, desde muito e tão abertamente esperada, a ofensiva Nivelle, a ofensiva mais inutilmente sangrenta dessa guerra imóvel e a que causa maior decepção: crise na moral dos exércitos, motins. Segue-se a onda de greves de maio-junho, já anunciada desde o inverno. Ela pouco atinge as fábricas de guerra, é uma onda de greves de operárias, a primeira desde o início da guerra, muito rápida e vigorosa.

Como exprimir o que está acontecendo? A pressão estaria forte demais? Pressão: uma força sobre uma superfície. $\mathrm{O}$ acúmulo acelerado de matéria e de morte, e o horizonte fechado demais, ocupado demais, denso demais, não aberto o suficiente, acúmulo de frio, de fome, cansaço, trabalho, mortos, mutilados, feridos, acidentes de trabalho, suicídios, lutos, desespero, lassidão, perturbação afetiva, violência, desamparo, humilhações, tensão pela vitória e raiva?

Subitamente, o cenário inteiro se altera. Como se tivesse havido uma implosão lenta e que vai se acelerando, tem a oclusão nessa primavera de 1917 e, então, a explosão. Compressão e, então, relaxamento.

Os Estados Unidos entraram na guerra em 6 de abril de 1917: vamos esperar por eles! E esperar que fiquem prontos os tanques de guerra, o automóvel operacional! Os heróis do mundo e da era taylorista e fordista são ali implantados, instaurados. O automóvel e os Estados Unidos: a vitória se deve a eles! Thomas é substituído pelo industrial Louis Loucheur, surge Clemenceau. O general Pétain é nomeado na primeira linha de frente. Depois de ser incumbido de eliminar os motins, prepara em campo a chegada dos norte-americanos e dos tanques. Pétain é o homem que organiza a espera.

Mas há também, em 15 de setembro, o fracasso da tentativa de realização de uma conferência da Internacional em Estocolmo. A II Internacional Socialista é virtualmente morta depois dessa tentativa de retorno à luz do dia. E chega outubro: Lênin fala, o proletariado está no poder. Ali estão os heróis do mundo e da era leninista. Nesse 7 de novembro dá-se seu duplo nascimento, enquanto ainda se ouvem os canhões no planalto de Craonne e em Chemin des Dames: são os operários (serão os operários especializados, os Carlitos de Tempos Modernos) e a revolução soviética.

$\mathrm{O}$ ano de 1917 inscreve quatro locais de investimento afetivo, quatro locais reais e simbólicos que serão, na França, rigorosamente inseparáveis, dois a dois, ao longo da era leninista-taylorista: o automóvel e os Estados Unidos para uns, os entusiastas da organização taylorista, que na verdade 
formam um trio; os operários e a União Soviética para outros, os loucos pela organização leninista, que formam outro trio.

A partir de 1917, uma única Revolução é representável, uma vez que se inscreveu, datou e localizou: a Revolução Soviética, para a qual se transfere o internacionalismo. Da mesma forma, o modelo fordista torna-se o modelo de crescimento capitalista. Par quiasmático constituído por setenta anos. Outro par quiasmático: o automóvel e os operários especializados, os operários da linha de montagem que o fabricam. O automóvel, símbolo da era taylorista, fornece ao leninismo seus operários símbolos, esse leninismo que os fixa como operários, "proletários", intimados a integrarem o tempo taylorista. A adesão incorpora-se ao respeito pelo tempo, e as duas regras se acumulam.

\section{Circulação e acumulação das regras: o caminho das Índias}

O ano de 1917 na verdade não passava, para os Estados Unidos de um lado, e para a Rússia de outro, de uma apresentação de candidatura à dominação do mundo. Por volta de 1929, Nova York sucede a Londres na longa série das economias-mundo dominantes ${ }^{20}$. Para evocar apenas a sequência enunciada por Braudel, insere-se no final de uma linha, cujo início este último situa em Veneza: seguem-se Antuérpia, Gênova, Amsterdã e Londres. A cada vez são criadas, desenvolvidas ou acumuladas as armas do poder: navegação, comércio, indústria, crédito, violência política. Londres é a primeira a reunir todas essas armas (cf. Braudel, 1979). Os Estados Unidos possuem seguramente outras especificidades, que Braudel não enuncia de modo explícito. Também por volta de 1929, a União Soviética oferece a si mesma, dentro do sistema instaurado pelos bolcheviques, os meios que lhe permitirão tornar-se, sem dúvida, por algum tempo, a segunda potência mundial. Quem poderia prevê-lo em 1929? A derrocada da União Soviética é, aliás, em certo sentido, bem braudeliana: como poderia este país se aguentar entre a antiga economia-mundo dominante centrada em Nova York e sua ferrenha concorrente resplandecendo em Tóquio?

Braudel, porém, escreve apenas sobre o campo da economia. Se pensarmos em técnicas, técnicas que são inseparáveis da organização, técnicas de navegação, de comércio, industriais, de crédito, de violência política etc., o cenário talvez se torne mais claro?

A potência norte-americana fundamentava-se em técnicas extensivas, no sentido de que estas se apoderavam do espaço: não só o automóvel que,
20. O termo não significa que essas economias abarcam o mundo inteiro, mas que são um mundo que se caracteriza por ser centrado (numa cidade), hierarquizado (em relação a zonas frágeis) e por ter limites (separando-o das demais economias) que variam lentamente. 
depois da estrada de ferro, fornecia-lhe a arma da conquista e do domínio do espaço terrestre, mas também a aviação, o telefone e outros sistemas de telecomunicação, ou ainda a ida para o espaço, tudo isso governado pela regra do respeito ao tempo. Desse ponto de vista, a experiência soviética constituiu um fracasso radical. A Revolução foi incapaz, inclusive, de conquistar, dominar e explorar o espaço terrestre de que dispunha quase que de saída: a Sibéria e a Ásia Central. Os êxitos aparentes, como a conquista espacial, eram apartados do mundo científico, técnico e industrial habitual: os êxitos técnicos eram operados em ilhas de segredo.

Assim também a regra de eficiência central, visando reduzir as resistências, era, na União Soviética, de outra ordem: a da adesão. Tal ordem, do respeito à fidelidade num sistema de produção de verdades sociais, supunha como principal operação técnica a eliminação dos portadores do erro: gulag. Soljenitsin assumiu em suas obras, principalmente em Arquipélago gulag, o papel do cronista historiógrafo do modo de produção da verdadeira expressão das necessidades sociais. Com títulos originados de metáforas técnicas, o mais longo capítulo da obra é o segundo, "História de nossas canalizaçōes", da primeira parte, chamada, por sua vez, "A indústria penitenciária". História de ondas, de fluxos que conduzem ao gulag, descrição da mímica insana com que Stálin imitou a contribuição essencial de Ford (o qual fascinava os soviéticos) à indústria: tornar fluido um meio que não o é naturalmente, a produção de objetos mecânicos complexos. Stálin fluidificou a produção da verdade. Técnica igualmente e perfeitamente extensiva.

Contudo cada sistema, a seu modo, deixou de lado a expressão dos desejos: um deles se constituiu em oposição aos desejos e apetites das "massas": eram qualificados de individuais, egoístas, burgueses; para o outro, a instituição de escritórios de organização e métodos não logrou reduzir todo refreamento do trabalho. Via o homem como material, como mecânica, como corpo, até que o reino da quantidade e da produção mecanizada, automatizada, esbarrasse não mais nas técnicas materiais, mas sim, nas relaçôes. Aí se abria o espaço dos técnicos do psicoafetivo.

No início do século, delimitando o inconsciente como território de intervenção, Freud afirmou que o irracional podia ser racionalmente apreendido. A psicanálise, naquela época ainda restrita ao gabinete do alienista, decretava sua regra fundamental, a da livre associação, graças à qual a produção da expressão do desejo verdadeiro poderia ser racionalizada, otimizada. A livre associação é uma regra que se incorpora historicamente àquelas, já acumuladas, do respeito pelo tempo e da adesão. 
No momento (presente: um momento de crise) em que a regra do respeito ao tempo sai de seu território de formulação - a produção industrial - para se estender a todas as produções (derrota e vitória do taylorismo), no momento em que a regra da adesão faz o mesmo, abandonando a representação da revolução para se estender a todas as representaçōes (derrota e vitória do leninismo), a regra da livre associação deixa o gabinete do alienista para se estender ao social, concluindo o percurso dos espaços de produção da sociedade.

A hipótese que apresento é a de que, ao final dos anos de 1960, iniciou-se um processo comparável à sequência 1900-1914-1917-1929 e não é impossível que estejamos numa data equivalente a 1917, senão a 1929 .

O momento de consenso, aquele que "faz época", como diz Marx acerca das revoluções de que procedem as acumulações primitivas (1969, p. 156), poderia ter se produzido, mundialmente, em torno de 1968 (momento em que já não é necessária a acumulação dos saberes da produção material). Mas onde e quando ocorrerá a primeira formalização, a que faz surgir o primeiro Mestre, a primeira encarnação, o primeiro avatar, da vontade da vez? As técnicas por vir que governariam as economias-mundo teriam (têm) um rosto como o de Ford, Stálin e Freud, um nome próprio ligado a um espaço ao qual prender o desejo, a projeção transferencial? Qual será a futura figura do Grande Irmão, já que há poucas chances de a humanidade - ainda - deixar de se dar um? Necessariamente inesperada, inédita, imprevista, equipada e paramentada com todos os adornos e atrativos da modernidade, provavelmente sem discurso, sem ideologia e sem princípio, uma figura quase impalpável, imaterial, quase indetectável, concentrada exclusivamente em sua operacionalidade, sua tecnicidade.

Tais técnicas serão (são) localizadas. Mas como, de acordo com que procedimentos, herdando que territorialidade (se, por exemplo, o comunismo foi russo sob a férula de um georgiano)? Procedendo por que modo de datação, isto é, de inscrição no sofrimento dos homens? Sob o governo de que regimes de ação?

Indo mais além, abusivamente talvez, a tal ponto que o futuro imaginado só a muito custo se distinga do presente, não poderíamos dizer que este momento é o momento de pelo menos dois outros heróis - ligados, como os anteriores, a um espaço? O primeiro, técnico, é o computador, ou antes, o microprocessador, inventado em 1970 nos Estados Unidos e integrado na prática pelo Japão ${ }^{21}$. É por meio dele que o proletariado de Marx é finalmente abolido e um dos sonhos de Marx é realizado: fim do trabalho manual, fim do esforço do trabalho físico, grande inflexão da história humana.
21. Assim como o automóvel foi inventado na França e integrado nos Estados Unidos. 
22. Ver, entre outros, o editorial da Far Eastern Economic Review, traduzido no Courrier International, n. 164, janeiro de 1994 23. A qual o genro de Marx, Paul Lafargue, deu um nome no século xIX: preguiça.

24. Outros, sem dúvida, ou os mesmos mais finamente enunciados: mas o pensamento das regras pressupóe uma estreita familiaridade com os tempos e os lugares, uma familiaridade de experiência, ainda que se possa admitir que ela jamais será completa.
As regras decretadas na indústria, na política e no governo de si mesmo e de suas relações (obrigação do respeito pelo tempo, obrigação de adesão social e obrigação de livre associação) perderam-se - lei espacial e coerente de estatística matemática - para se tornarem operacionais e se estenderem na vida, suas unidades de formação, seus territórios de formulação.

O tempo de trabalho é passível de ser totalmente integrado no (bio)-microprocessador, e a adesão, de ser organizada na associação livre gerida pelos especialistas da comunicação, dos desejos, dos sonhos e das paixões.

O segundo herói dessa nova era são as mulheres, "proletariado" novo, fonte de acumulação, com um trunfo que não é senão o controle da fecundidade, da produção da vida humana. Esse "proletariado", tal como o anterior, prepara sua própria abolição, de conluio com/contra seu irredutível adversário. $\mathrm{O}$ centro de padronização dessa nova era é Pequim, capital de um país onde as agressões ao corpo das mulheres nunca foram tão brutais e sistemáticas, e o eugenismo, técnica de controle absoluto da população, nunca atingiu tais patamares ${ }^{22}$.

Para todos os demais, com exceção das mulheres, a quinta regra cumprir-se-ia simultaneamente à livre associação, acumulando-se às outras quatro: a regra do mínimo dispêndio de energia não mecanizada ${ }^{23}$. Restaria tão somente o esforço, a servidão biológica da gestação, que ciências e técnica somadas fazem de tudo para diminuir, senão suprimir. Uma vez vencida essa derradeira escravidão, a humanidade seria libertada de todo cansaço, de todo esforço, todo conflito, todo motivo para dispêndio de energia, da parte lógica do pensamento, do trabalho. Toda moral, cansativa, seria então sem objeto. A humanidade seria libertada do parto de si mesma, cumprido com dor. Poderia, enfim, se comprazer parindo apenas o espírito: opondo-se a Zenão de Eleia, Sócrates declarou esta necessidade e, com sua morte, ofereceu voluntariamente o programa.

Os tempos não estão mais, com efeito, para técnicas extensivas e sim, com o mundo girando rumo ao inexpiável enfrentamento entre Japão e China (países de densas populaçôes, espaço vital reduzido, território unificado, cultura nacional profunda e antiga), para técnicas intensivas, concentradas, para as quais a informática e as biotecnologias abrem a possibilidade certeira.

Junto com o percurso do mundo, operou-se aquele das regras fundamentais de efetividade acumuladas, abarcando desde as origens uma variedade de quadros de valorização, a existência, a nominação, o cálculo, a efetividade em si (o reinado da técnica), a relação política, a afetividade, a moral ${ }^{24}$. Ao final, sobraria a estética para dar à Terra mais uma oportunidade de girar. 
A vez (dos técnicos do cérebro?) seria então da Índia (dentro de uns sessenta anos? Um século?) para que se cumpra a regra da contemplação, na qual as outras todas poderão se fundir. Antes de um novo giro da Terra.

Clamart, março de 1981 e setembro de 1994

\section{Referências Bibliográficas}

Braudel, Fernand. (1979), Civilisation matérielle, économie et capitalisme XV $V^{e}-X V I I I^{e}$ siècle: le temps du monde: Paris, Armand Colin, vol. 3.

Cohen, Yves. (1986), "Le système de la pratique: un organisateur-directeur, les automobiles Peugeot, 1917-1939”. Actes du Gerpisa, 2: 3-23. (2001), Organiser à l'aube du taylorisme: la pratique d'Ernest Mattern chez Peugeot, 1906-1919. Besançon, Presses Universitaires Franc-Comtoises. [Referência acrescentada em 2012]

Fine, Martin. (1978), "Guerre et réformisme en France”. In: Murard, Lion \& Zylberman, Patrick. (dir.). Le soldat du travail: guerre, facisme et taylorisme. Paris, Recherches, pp. 305-24.

Freud, Sigmund. (1973), Introduction à la psychanalyse. Paris, Payot.

Fridenson, Patrick (dir.). (1977), 1914-1918, l'autre front. Paris, Ouvrières.

Foucault, Michel. (1975), Surveiller et punir. Paris, Gallimard.

Hoвsваwм, Eric. (2009), Era dos extremos: o breve século XX (1914-1991). São Paulo, Companhia das Letras.

JaKobson, Roman. (1963), Essais de linguistique générale. Paris, Minuit.

MarX, Karl. (1969), Le capital. Paris, Sociales.

Mauss, Marcel. (1983), "Les techniques du corps". In: Sociologie et anthropologie. Paris, PUF, pp. 365-88.

MоттеZ, Bernard. (1966), Systèmes de salaire et politiques patronales: essai sur l'évolution des pratiques et des idéologies patronales. Paris, CNRS.

(1975), La sociologie industrielle. Paris, PUF.

Perrot, Michelle. (1980), L’impossible prison. Paris, Seuil.

SCHORSKe, Carl. (1988), Viena fin-de-siècle: política e cultura. São Paulo, Companhia das Letras.

Soljenitsin, Alexandre. (1973), Arquipélago gulag: 1918-1956. São Paulo, Círculo do Livro. [Referência acrescentada em 2012.]

TAYLOR, Frederick. (1957), La direction scientifique des entreprises. Paris, Dunod.

Wallon, Henri. (1936), "Psychologie et technique”. In: A la lumière du marxisme. Paris, Sociales Internationales. 


\section{Resumo}

\section{O século de Taylor, Lênin e Freud}

Este artigo percorre o século Xx do ponto de vista da prática. Ele mostra que três regimes de regulação das práticas, quais sejam, o taylorismo, o leninismo e a psicanálise, lançaram seus programas em 1900, cada um em seu domínio, porém partilhando a mesma relação organizada entre a pretensão científica e a ação (dos operários para o primeiro, das massas para o segundo e do paciente em sessão para o terceiro, todos sob a direção de profissionais). Cada um desses regimes teve, durante décadas, seu lugar de inscrição e de peregrinação, bem como os portadores que os encarnavam. Eles formalizaram os quadros de valorização que são a eficácia, a luta política e o equilíbrio psicoafetivo. $\mathrm{O}$ artigo trata de modo aprofundado da prática taylorista de concepção das normas da prática dos outros ao identificar as diversas variáveis desta (o objeto, a referência, a temporalidade, o espaço, a serialização, a materialidade, os funcionários etc.). Conclui esboçando um cenário da história do século XX como circulação de práticas de um quadro de valorização a outro (a existência, a nominação, o cálculo, a eficácia, a política, o afetivo, a ética, a estética) e, desse modo, de uma região do mundo a outra a fim de seguir suas inscrições primordiais.

Palavras-chave: Taylorismo; Leninismo; Psicanálise; Prática; História mundial; Circulações.

\section{Abstract}

\section{The century of Taylor, Lenin and Freud}

This article examines the notion of practice over the course of the twentieth century. It shows that three systems of regulating practices - namely Taylorism, Leninism and psychoanalysis - launched their programs in 1900, each within its own specific domain but sharing the same organized relationship between scientific claims and action (of the workers in the first case, the masses in the second and the patient under analysis in the third, all under the direction of professionals). For decades, each of these systems had its place of inscription and migration, along with the people who embodied them. They formalized the valuation frameworks comprised by efficiency, political struggle and psycho-affective equilibrium. The article provides an in-depth analysis of the Taylorist

Texto recebido em 17/5/2011 e aprovado em 6/8/2012.

Yves Cohen é professor no Centre de Recherches Historiques, École des Hautes Études en Sciences Sociales. E-mail: <yvecohen@ free.fr>.

Errata: Na edição impressa, em vez de Dorothée Buchard, o nome correto da tradutora deste artigo é Dorothée Bruchard conception of the norms of other people's practice by identifying the diverse variables of the latter (object, reference, temporality, space, serialization, materiality, employees, etc.). It concludes by providing a sketch of twentieth century history as a circulation of practices from a framework of valorizing the other (existence, a nomination, calculation, efficiency, politics, affect, ethics, aesthetics) and, consequently, from one region of the world to another in pursuit of its primordial inscriptions.

Keywords: Taylorism; Leninism; Psychoanalysis; Practice; World history; Circulations. 